\title{
Family hardship and children's development: the early years
}

\author{
Ingrid Schoon*, Steven Hope\#, Andy Ross\#, and Kathryn Duckworth* \\ *Institute of Education, London \\ \#National Centre for Social Research \\ I.Schoon@ioe.ac.uk
}

Received May 2010 Revised June 2010)

\section{Abstract}

Examining the factors and processes shaping school readiness provides important information about how to enable young children to develop their cognitive potential and to succeed in their school careers. The aim of this paper is to assess different mediating processes through which family hardship affects children's early development, both in terms of cognitive and behavioural adjustment. Using data from the UK Millennium Cohort, we examine the associations between persistent socio-economic hardship and young children's development, and investigate the role of maternal emotional distress, mother-child interactions, and cognitive stimulation as potential mediators, in a sample of 14661 children, who were followed from birth through age 3 years. Cognitive ability was assessed by standardized tests, and child behaviour by maternal report, when the children were 3 years of age. The findings suggest that persistent family hardship was significantly associated with child developmental outcomes. The impact of hardship on cognitive and behavioural adjustment is partially mediated by the level of maternal distress, which in turn shapes the quality of parent-child interactions and the provision of a cognitively stimulating home environment. The findings suggest differential pathways in the transmission of family disadvantage, where parenting characteristics were more important in mediating the effect of hardship on behavioural adjustment, than on early cognitive development. Findings are discussed in terms of their policy implications.

Characteristics of children at school entry, provide vital clues for predicting their performance during their school careers and for later development. Moving beyond a narrow view of school readiness defined by measures of children's cognitive capacities, more holistic approaches, including indicators of socio-emotional and behavioural adjustment, have shown to be more useful indicators of early functioning (Alexander 2009; Kagan 1992; Meisels 1999), as both the possession and implementation of skills are important. The development of cognitive, behavioural, physical, and socio-emotional capacities in the early years, forms the foundation of wellbeing, learning and behaviour across the life course and is crucial in shaping later developmental adjustment (Duncan et al 2007; Heckman 2006; Marmot 2010; McLoyd 1998; Rutter 1989). Previous research has shown that differences in capabilities that exist at the beginning of school are likely to perpetuate over time (Entwistle and Alexander 1999; Feinstein and Bynner 2004; Schoon 2006). Indeed the early years have been identified as 
a crucial window for interventions, a sensitive period for skill formation (Heckman 2006), especially regarding cognitive development (Sameroff, Seifer, Baldwin and Baldwin 1993; Schuerger and Witt 1989). Gaining a better understanding of early influences on school readiness, is thus vitally important in enabling young children to fully develop their potential. In the following, we adopt a more holistic view of school readiness, focusing on both cognitive and behavioural outcomes, and examine the role of family hardship in influencing the child's development in the first three years of life. Both academic and behavioural adjustment are understood as markers of key capabilities at school entry, enabling the child to meet the demands of schooling (Janus and Duku 2007; Lloyd and Hertzman 2009). We furthermore examine the role of parent characteristics and parent-child interactions as mediators impacting on the association between hardship and child adjustment, in order to identify potential protective mechanisms and processes enabling children to strive against the odds.

\section{Socio-economic adversity and early adjustment}

There is ample evidence of the association between family hardship and children's cognitive and behavioural development (Bradley and Corwyn 2002; Duncan and Brooks-Gunn 1997; Keating and Hertzman 1999). Relative few studies, however, have focused on early childhood (Linver, Brooks-Gunn and Kohen 2002; Kiernan and Huerta 2008; Kiernan and Mensah 2009; Robila and Krishnakumar 2006; Waldfogel and Washbrook 2010), when the effects of material hardship appear to be strongest (BrooksGunn and Duncan 1997; Korenman, Miller, and Sjaastad 1995; Plewis and Kallis 2008). There is evidence to suggest that cognitive development in the early years is malleable in response to environmental conditions. For example, in a study based on a sub-sample of the 1970 British cohort study, Feinstein (2003) showed that differences in cognitive development associated with income inequalities, emerge as early as 22 months. The gap appeared to widen as children aged, and around age 6 , children in the highest achieving group, with parents in the least privileged socio-economic group, were overtaken by children from advantaged backgrounds, who were in the low-achieving group at age 22 months. Studies drawing on data collected for the most recent UK Millennium Cohort, confirm the corrosive effects of poverty on children's cognitive development, as well as their psycho-social adjustment in early childhood (Blanden and Machin, 2010; George, Hansen, and Schoon, 2007; Kiernan and Huerta, 2008; Kiernan and Mensah 2009; Waldfogel and Washbrook 2010). Furthermore, research findings based on the British Cohort Studies, highlight that early disadvantage can have important consequences and undermine later achievements. The experience of family hardship in the early years, undermines early cognitive development and psychosocial adjustment, which in turn influences later attainments, as shown in follow-up studies of the 1958 and the1970 cohort (Bynner and Joshi 2002; Bynner, Schuller and Feinstein 2003; Feinstein 2004; Feinstein and Vignoles 2008; Schoon 2006; Schoon et al 2002).

\section{Beyond income}

Much of the research to date on poverty effects on child development has focused on the effects of income (Blanden and Gregg 2004; Blanden and Machin 2010; Waldfogel and Washbrook 2010); (see also Gregg and Macmillan in this Special Issue). This is not surprising, given that income poverty rates in the UK remain high. At the turn of the Millennium about 26 per cent of children lived in households with an equivalised houshold income below 60 per cent of the national median. Between 1998/9 and 2004, this rate fell to 21 per cent, but has increased to 23 per cent in 2009 (Hills, Sefton and Steward,2009; Maclnnes, Kenway and Parekh 2009). Given the persistence of extreme poverty even in highly developed countries, it is essential for developmental scientists to learn more about the impact of poverty and material hardship on families and children living today.

In analysing effects of poverty on children's development, one should however not forget about the families whose income is considered as 'low income' just above the threshold of the poverty line. Children in these low income families experience many of the same hardships as children in families defined as income poor, such as housing insecurity, overcrowding, lack of amenities, or dependence on state benefits to make ends meet. Consideration of 
the linked contributions of family income and material hardship has thus been recommended to gain a better understanding of the corrosive effects of family poverty on children's development (Gershoff, Aber, Raver and Lennon 2007; Plewis and Kallis 2008; Yeung, Linver and Brooks-Gunn 2002).

\section{Mediating processes}

Although the association between family hardship and child development is well documented, the ways in which the experience of socio-economic hardship influences children's development have been less well studied. Family interactions, neighbourhood processes, and child-care quality have been shown to mediate the effect of family hardship on child development, illustrating the contextualized nature of early child development (Brooks-Gunn and Duncan 1997; McLoyd 1994; McLoyd and Flanagan 1990). There is evidence of promising effects of early intervention programs, such as Sure Start in the UK, which can improve the life chances of young children (Melhuish, Belsky, Leyland, and Barnes, 2008). Indeed, there is persistent research evidence to suggest that early developmental trajectories can change over time (Feinstein 2003; Rutter 1989; Schoon 2006). It is thus vital to learn more about the factors and processes that can potentially ameliorate the negative impact of poverty on children's early development. For example, economic hardship has a differential effect on specific child outcomes, generally exhibiting a stronger effect on children's cognitive development than on behaviour (Conger and Elder 1994; Kiernan and Huerta 2008; Kiernan and Mensah 2009; Linver et al 2002; Plewis and Kallis 2008; Schoon, Cheng and Jones 2010). We thus will examine the pathways linking family hardship to cognitive and behavioural adjustment separately. The lack of understanding of how the experience of hardship influences child development, has greatly hampered the ability of policy makers to design effective interventions to improve children's development and wellbeing.

Theoretical models linking the experience of material hardship to child outcomes have focused in particular on the mediating role of family psychological stress (Conger and Elder 1994; Mistry, Biesanz, Taylor, Burchinal and Cox 2004; Yeung et al 2002), parent's investments of time or money in their children (Guo and Harris 2000), or a combination of these factors (Gershoff et al 2007; Kiernan and Mensah 2009; Linver, Brooks-Gunn and Kohen 2002; Yeung et al 2002). The family investment model asserts that income is associated with children's development, because it limits the amount of resources, including money, time, energy, and support, they have available for their children (Becker and Thomes 1986; Haveman and Wolfe 1994; Mayer 1997). It does however, not specify how economic circumstances might impact the quality of parentchild interactions. The family stress model, on the other hand, postulates that family hardship influences children's cognitive development and behaviour through parental emotional distress resulting from financial strain, which negatively influences parenting practices, which are in turn associated with poorer child outcomes (Conger, Ge, Elder, Lorenz and Simons 1994; Conger et al 1992, 1993; Elder and Caspi 1988; McLoyd 1989; McLoyd 1994). It has also been shown that parental psychological distress impacts on parent's abilities or willingness to invest in their children, suggesting the appropriateness of combining both models (Gershoff et al 2007; Kiernan and Huerta 2008; Linver et al 2002; Yeung et al 2002). However, there is also evidence to suggest that different components of the family environment may have differential effects on child outcomes. While the provision of stimulating experiences in the home environment is shown to be more strongly associated with children's cognitive development than with behavioural adjustment, parent-child relations were more strongly associated with children's behaviour (Linver et al 2002; Kiernan and Huerta 2008). It is thus important to differentiate between cognitive and emotional components of parenting, and to assess their relative impact on child adjustment.

In the following we will test the usefulness of combining the family stress and investment model to explain variations in early adjustment, by drawing on data collected for the UK Millennium Cohort. We will assess the relative sizes of associations when considering several aspects simultaneously, as well as in their separate effects. Adding to the existing few studies examining the mediating processes by which family economic hardship influences cognitive and behavioural development of young children, we will take into account the effects of persistent hardship 
and persistent maternal stress during early childhood, and their impact on school readiness and behavioural adjustment by age 3 . In addition, instead of focusing on household income (Kiernan and Mensah 2009), we take into account material resources available to the family at age 9 months and 3 years, to account for persistence of family hardship. Furthermore, we conceptually differentiate between proximal and distal processes (Bronfenbrenner 1979), following the assumption that the strongest influence on children's development are processes and interactions directly experienced by the child, such as parenting behaviour. Distal characteristics, such as family income and material hardship, impact on children insofar as they shape these proximal processes. Furthermore, we take account of a number of background, or control variables to ensure that the predicted findings were not spurious. It has been argued that economic hardship has little, or no, direct effect on children's outcomes, which are largely due to other characteristics of the parents, such as parental education (Rowe and Roger 1997). We thus control for maternal education, as well as maternal age, ethnicity, marital status at birth, total number of siblings living in the household, sex of the child, low birthweight (<2500 grams) and prematurity. Including these basic demographic characteristics in the model gives greater confidence in the links between the variables included in the model.

Following from previous research, we tested the following hypotheses: a.) family hardship is directly associated with child outcomes, although the association may vary across different outcomes, i.e. cognitive and behavioural adjustment; b.) the association between family hardship and child outcomes persists after controlling for sociodemographic characteristics of the family and biological risk factors; c.) the association between family hardship and child outcomes is mediated by i.) constructs of the family stress model; ii.) the family investment model; iii.) by the combination of both models.

\section{Method}

\section{Sample}

The study draws on data collected for the Millennium Cohort Study (MCS), a survey of 18,819 babies born between September 2000 and January
2002 into 18,553 families living in the UK (Dex and Joshi 2005). The first sweep of the Millennium Cohort Study was carried out during 2001 and 2002 when most babies were 9-months old. The sample design allowed for disproportionate representation of families living in areas of child poverty. Electoral wards based on 1998 geography were used as the sampling frame and information about child poverty was incorporated as provided in the Index of Deprivation (Noble et al 2000). Due to disproportionate sampling, special weights have to be applied in analyzing the data (Plewis, Calderwood, Hawkes, Hughes, and Joshi 2004).

Data were collected from the parents of the babies via personal interview and self-completion questionnaire, as well as direct assessment of children's cognitive abilities (Plewis et al 2004; Shepherd, Smith, Joshi and Dex 2004). The following analyses are based on 14,661 singleton babies, with data from the 9 and 36 month data collection sweeps.

\section{Measures}

\section{Focal variable: material hardship}

An index of family material hardship was created, based on five indicators assessed at both age 9 months and 3 years, including low net household income [less than $£ 10,400$ per annum, which represents the bottom quartile], receipt of income support (a means-tested benefit), access to a car or van, as well as housing-based measures including home ownership and overcrowding [more than one person per room]. The individual items were dichotomised to create a summary hardship index for each time point, with an observed range of 0 to 5 . Scale values of four and five were combined due to small numbers, and indicate severe levels of hardship, while a score of 0 indicates lack of hardship. There was a strong correlation between reported hardship at the two ages $(r=0.81)$.

\section{Mediating variables}

Maternal emotional distress was assessed when the child was 9 months and 3 years old. At age 9 months (in 2000/1) a shortened 9-item version of the Rutter Malaise Inventory (Rutter, Tizard and Whitmore 1970) was used. The Malaise Inventory is a selfcompletion measure that has been widely used as a measure of depression, anxiety and psychosomatic 
illness in general population studies (McGee, Williams and Silva 1986; Rodgers, Pickles, Power, Collishaw and Maughan 1999) as well as in investigations of high-risk groups, notably informal carers (Grant, Nolan, and Ellis 1990). The shortened scale ranges from 0 to 9 , has acceptable internal consistency (Cronbach's alpha $=.73$ ), and correlates significantly with previously diagnosed and currently treated depression.

At age 3 (in 2003/4) the 6 item Kessler psychological distress scale (K6) was used for the identification of maternal anxiety and depression. The K6 is a widely used screening instrument, which has been especially developed for use in population surveys (Kessler et al 2002). Responses are given on a four-point Likert scale and are summed to produce a uni-dimensional scale (alpha for the $\mathrm{MCS}=0.86$ ) with a range of 0 to 24 . The two measures of psychological distress are moderately correlated $(r=0.47)$.

Parent-child relationship was assessed at age 3 years using the Pianta scale (Pianta 1992), a 15 item selfadministered rating scale with responses on a 5-point Likert scale. A total score was derived, with a high score reflecting an overall positive relationship. The alpha coefficient for the Pianta scale in the MCS sample was .77 .

Cognitive stimulation at age 3 years was measured on the basis of maternal report on whether the child was read to, taught the alphabet, counting or songs, at least once a week, and whether the parents took the child on visits to the library. The five items were summed to an index of cognitive stimulation ranging from 0 to 5 .

\section{Child Outcomes at age 3}

School Readiness was assessed with the Bracken School Readiness Assessment (BSRA) which was individually administered to each child. The BSRA comprises six subtests measuring children's knowledge of colours, letters, numbers, sizes, comparisons of objects, and shapes (Bracken 2002). It is a developmentally sensitive measure of children's basic concept acquisition and receptive language skills, designed for children ages two and a half through to age seven. The BSRA has strong psychometric characteristics and good validity (Panter and Bracken 2009). In the following analysis we use age-standardised scores.

Behavioural adjustment is measured with the Strength and Difficulties Questionnaire (SDQ), a behavioural screening questionnaire for 3 to 16 years olds (Goodman 1997, 2001). It consists of 25 items, assessed via parental report, generating an overall scale score as well as scores for five subscales: conduct problems, hyperactivity, emotional symptoms, peer problems and pro-social behaviour. For the following analysis, an overall difficulties mean score for the whole sample, was computed by summing replies to the subscales indicating behaviour problems, i.e. conduct problems, hyperactivity, emotional symptoms, and peer problems.

\section{Control variables}

A number of control variables were included in the analysis to make sure that the results are not spurious:

- Mother's age at birth of child

- Mother's marital status at the birth of the child

- Mother's education (below GCSE versus GCSE and above)

- Mother's ethnicity (white versus other)

- Total number of children living in household

- Baby gender (male, female)

- Prematurity (gestation period less than 37 weeks)

- Low birthweight (less than 2500 grams)

\section{Analytic Strategy}

Structural equation modeling was used to assess the pathways linking family hardship to children's developmental outcomes at age 3 years. All analyses were carried out using the statistical package Mplus 5 (Muthén and Muthén 2007). This method allows analysis of cases with missing data under the assumption that the data are missing at random (Little and Rubin 2002). Probit regressions were used based on robust weighted least squares estimation. Because some of the dichotomised variables functioned as both independent and dependent variables in the conceptual model, the theta 
parameterization was necessary. Regression estimates convert probit estimates for ordinal dependent variables to a common metric that allows comparison with standardised linear regression estimates for the continuous variables.

In line with current practice, several criteria were used to assess the fit of the data to the model. The $\chi^{2}$ statistic is overly sensitive to model mis-specification when sample sizes are large, or the observed variables are non-normally distributed. The root mean square error of approximation (RMSEA) gives a measure of the discrepancy in fit per degrees of freedom (e.g. values less than .05 indicate a good fit). The final index of choice is the comparative fit index (CFI), indicating if the model provides significantly better explanation of the relations between variables than the null hypothesis-model with no relations between variables. Values above .95 indicate an acceptable fit (Bentler 1990).

In a first step, bivariate Pearson's correlations between variables were calculated. Table 1 shows means, standard deviations and correlations between variables under study. In the next step the authors investigated the association between family adversity and child outcomes as well as mediator effects for cognitive and behavioural adjustment separately. To decompose the relative impact of family hardship, control variables, and mediating variables, we tested separate models. Model a establishes the direct link between hardship and child outcomes. Model $b$ adds the control variables, and model c, the mediating variables. This analysis sequence allowed the examination of whether the relationship between family hardship is partially or fully mediated by the addition of the control variables and the mediators. Furthermore, different models were tested to assess whether family stress constructs, a parental investment measure (i.e. cognitive stimulation), or both, act as mediators of the relations between family hardship and child outcomes. 
Table 1: Means, Standard Deviations, and bivariate Pearson Correlations between variables included in the model

\begin{tabular}{|c|c|c|c|c|c|c|c|c|c|c|c|c|c|c|c|c|c|c|}
\hline Variables & 1 & 2 & 3 & 4 & 5 & 6 & 7 & 8 & 9 & 10 & 11 & 12 & 13 & 14 & 15 & 16 & $M$ & $S D$ \\
\hline $\begin{array}{l}\text { 1. Material } \\
\text { hardship ( } 9 \\
\text { mths) }\end{array}$ & 1.00 & & & & & & & & & & & & & & & & 1.06 & 1.38 \\
\hline $\begin{array}{l}\text { 2. Material } \\
\text { hardship } \\
\text { (36 mths) }\end{array}$ & $.81^{* *}$ & 1.00 & & & & & & & & & & & & & & & 0.96 & 1.33 \\
\hline 3. Bracken & $-.34 * *$ & $-.34 * *$ & 1.00 & & & & & & & & & & & & & & 103.69 & 16.29 \\
\hline 4. SDQ & $.31^{* *}$ & $.31^{* *}$ & $-.29 * *$ & 1.00 & & & & & & & & & & & & & 9.55 & 5.26 \\
\hline $\begin{array}{l}\text { 5. Malaise } \\
\text { (9 months) }\end{array}$ & $.18^{* *}$ & $.18^{* *}$ & $-.10 * *$ & $.28^{* *}$ & 1.00 & & & & & & & & & & & & 1.67 & 1.76 \\
\hline $\begin{array}{l}\text { 6. Kessler } \\
\text { (36 mths) }\end{array}$ & $.25^{* *}$ & $.27^{* *}$ & $-.17^{* *}$ & $.36 * *$ & $.47^{* *}$ & 1.00 & & & & & & & & & & & 3.54 & 3.86 \\
\hline 7. Pianta & $-.19 * *$ & $-.18 * *$ & $.17^{* *}$ & $-.61 * *$ & $-.27 * *$ & $-.37 * *$ & 1.00 & & & & & & & & & & 64.51 & 6.86 \\
\hline $\begin{array}{l}\text { 8. Cogn } \\
\text { stimulation }\end{array}$ & $-.15^{* *}$ & $-.15^{* *}$ & $.26 * *$ & $-.17^{* *}$ & $-.06 * *$ & $-.09 * *$ & $.11^{* *}$ & 1.00 & & & & & & & & & 3.74 & 0.99 \\
\hline $\begin{array}{l}\text { 9. Maternal } \\
\text { ethnicity }\end{array}$ & $-.18 * *$ & $-.15^{* *}$ & $.21 * *$ & $-.10 * *$ & $-.05 * *$ & $-.12 * *$ & $.02 *$ & $.13^{* *}$ & 1.00 & & & & & & & & 0.85 & 0.54 \\
\hline $\begin{array}{l}\text { 10.Maternal } \\
\text { age }\end{array}$ & $-.42 * *$ & $-.40 * *$ & $.18^{* *}$ & $-.23 * *$ & $-.08 * *$ & $-.12 * *$ & $.15^{* *}$ & $-.05 *$ & $.04 * *$ & 1.00 & & & & & & & 28.66 & 5.87 \\
\hline $\begin{array}{l}\text { 11.Maternal } \\
\text { education }\end{array}$ & $-.41 * *$ & $-.40 * *$ & $.29 * *$ & $-.24 * *$ & $-.09 * *$ & $-.15^{* *}$ & $.11^{* *}$ & $.18^{* *}$ & $.17^{* *}$ & $.18^{* *}$ & 1.00 & & & & & & 0.77 & 0.42 \\
\hline $\begin{array}{l}\text { 12. Married } \\
\text { at birth }\end{array}$ & $-.59 * *$ & $-.53 * *$ & $.17^{* *}$ & $-.18^{* *}$ & $-.09 * *$ & $-.15^{* *}$ & $.12^{* *}$ & $.06 * *$ & $.03 * *$ & $.29 * *$ & $.21 * *$ & 1.00 & & & & & 0.83 & 0.37 \\
\hline $\begin{array}{l}\text { 13. Nr of } \\
\text { children }\end{array}$ & $.13^{* *}$ & $.12^{* *}$ & $-.23 * *$ & .01 & $.06 * *$ & $.06 * *$ & $.06 * *$ & $-.14^{* *}$ & $-.12 * *$ & $.32 * *$ & $-.19 * *$ & $.04 * *$ & 1.00 & & & & 0.94 & 1.06 \\
\hline $\begin{array}{l}\text { 14. Birth- } \\
\text { weight low) }\end{array}$ & $.06 * *$ & $.06 * *$ & $-.07 * *$ & $.06 * *$ & $.04 * *$ & $.05 * *$ & $-.02 *$ & $.03 * *$ & $-.09 * *$ & -.01 & $-.06 * *$ & $-.03 * *$ & -.05 & 1.00 & & & 0.06 & 0.24 \\
\hline $\begin{array}{l}15 . \\
\text { Gestation } \\
\text { (premature) }\end{array}$ & $.03 *$ & $.03 * *$ & $-.04 * *$ & $.04 * *$ & $.03 *$ & $.04 * *$ & -.01 & .00 & -.01 & -.00 & -.01 & $-.02 *$ & -.01 & $.50 * *$ & 1.00 & & 0.07 & 0.25 \\
\hline $\begin{array}{l}\text { 16. Gender } \\
\text { (female) }\end{array}$ & .00 & .01 & $.12^{* *}$ & $-.10 * *$ & $-.02 *$ & -.01 & $.06 * *$ & $.07 * *$ & -.01 & .00 & .01 & .00 & .00 & $.02 \dagger$ & -.01 & 1.00 & 0.49 & 0.50 \\
\hline
\end{tabular}




\section{Results}

Figure 1 shows the structural equation model assessing the pathways linking family hardship to school readiness. The usual structural equation modeling conventions are used, depicting latent variables as a circle, and manifest variables in rectangles. The two latent variables comprise indicators of family hardship on the one hand, and maternal distress on the other, providing measures of persistent hardship and persistent distress, averaging the experiences at age 9 months and 3 years. Unique and error variance for each manifest variable and disturbance on the latent variables are included in the model (not shown in the diagram). Path estimates are given as standardised regression coefficients, that may be squared to obtain the variance shared by adjacent variables. All paths in the model were significant at the $5 \%$ level (parameter estimates divided by their standard errors), and the model provides a good fit to the data.

Figure 1. Predicting school readiness at age 3: the full model

(a. no mediators no controls, b. no mediators with controls, c. with mediators and controls)

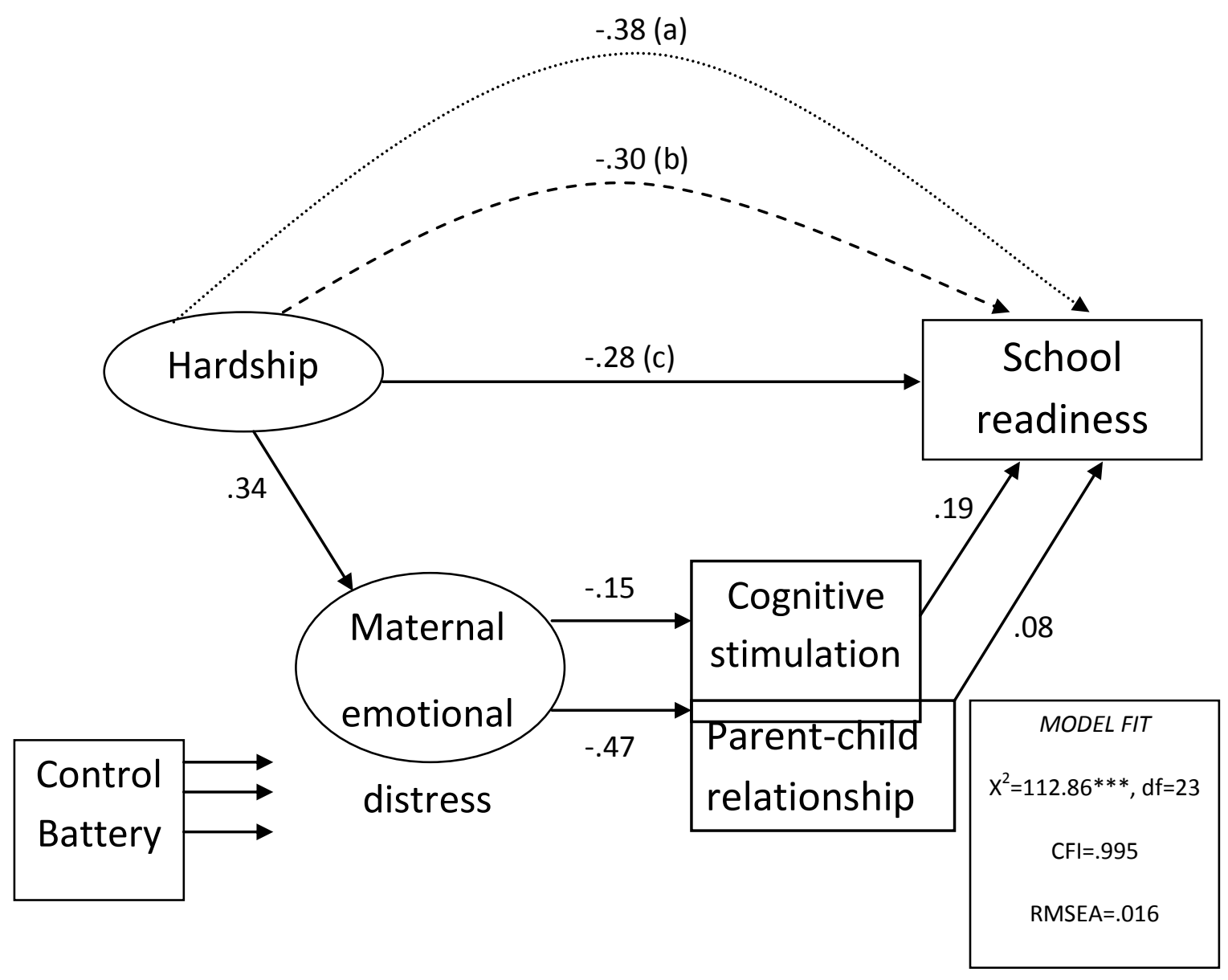


The association between family hardship and cognitive ability was statistically significant, both without ( $(=-.38)$ and with controls $(\beta=-.30)$. With controls the model explained $19 \%$ of the variance in cognitive ability. After adding the mediators, the path from family hardship to child cognitive development reduced to $\beta=-.28$, suggesting that parenting factors only partially mediate the association between poverty and cognitive development. Adding the parenting characteristics enables us to explain an additional $4 \%$ of variance in school readiness, in addition to that explained by family poverty and controls.

Figure 2. Predicting behaviour adjustment at age 3: the full model

a. no mediators no controls, b. no mediators with controls, c. with mediators and controls)

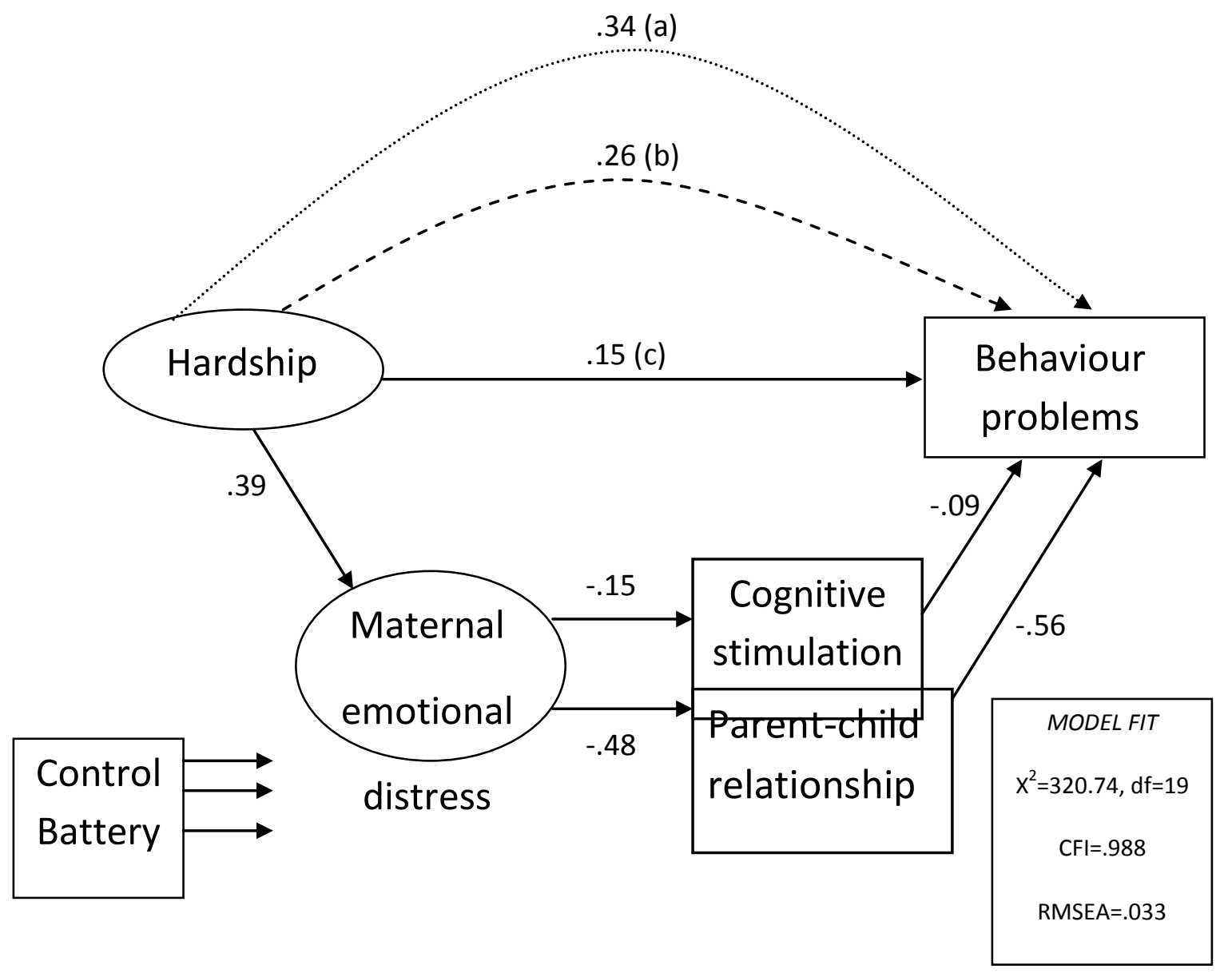

In a next step we assessed the pathways linking family hardship to behavioural adjustment (Figure 2). Family hardship was significantly associated with behaviour problems ( $\beta=-.34)$. Adding the control variables reduces the direct association to $\beta=-.26$. When the controls are included, the model explained 14 per cent of the variance in behaviour problems.
The full model, depicted in Figure 2 shows the combination of both family stress and family investment constructs. After adding all the mediators we can explain an additional 32 per cent of the variance in behavioural adjustment, and the path from family hardship to child cognitive development reduced to $\beta=-.15$. 


\section{Discussion}

The study illustrates the corrosive effect of family hardship on the cognitive development and behavioural adjustment of young children. The experience of hardship in the first three years of life undermines the formation of skills that are necessary for the child to succeed in their school careers. The study furthermore identifies the role of characteristics in the family environment as potential mediators, differentiating between the impact of constructs identified within the family stress and the family investment models. In particular, the study tests the viability of combining both models to gain a better understanding of how family hardship is associated with early developmental outcomes (see also Linver et al 2002). Constructs of both models mediated the association between family hardship and child development. However, the provision of stimulating experiences in the home appears to be more important for the cognitive development of the child, while family stress constructs emphasizing the role of maternal distress and less-involved parenting, appear to be especially important for behavioural adjustment (see also Linver et al 2002; Kiernan and Huerta 2008; Yeung, Linver, and Brooks-Gunn 2002). While parenting characteristics explained relative little of the variation in cognitive development, in addition to the influence of family hardship and the control variables, they were crucial in reducing the negative impact of family hardship on behavioural adjustment.

Furthermore, combining both models enabled us to illustrate how distal influences impact on more proximal experiences of the child, and to identify the role of persistent maternal distress as a mediating factor, linking family hardship to parenting behaviour as well as cognitive stimulation, which in turn influences children's development. Maternal depression is generally considered a risk factor for poor socio-emotional and cognitive development (Cummings and Davies 1994), although the associations between maternal depression and child outcomes are complex (Downey and Coyne 1990), and not all studies have found a relationship between maternal distress and cognitive development (Kiernan and Huerta 2008; Linver, Brooks-Gunn and Kohen 2002). Variations in severity, chronicity, and timing of depression (Campbell, Cohn and Meyers 1995), as well as heterogeneity in sampling and other potential risk factors such as low social support, can contribute to differences in child outcomes (Sameroff et al 1993). In this study, the authors accounted for persistence of maternal distress between ages 9 months and 3 years, and found that mothers exposed to persistent hardship, with reduced access to economic resources, are more likely to experience continued stress, which in turn is associated with reduced investment in their children (in terms of cognitive stimulation) as well as less involved parentchild interactions, which in turn are associated with their children's developmental outcomes. These associations were significant even after controlling for a number of background characteristics, such as mother's education, ethnicity, and marital status, as well as indictors of early biological risk, to ensure that the findings were not spurious. It should be noted that in another study also using the Millennium cohort, the association between persistent maternal distress and cognitive functioning was also apparent (Kiernan and Mensah 2009).

In interpreting the findings, a number of limitations have to be considered: the hypothesized pathways examined in the model, test specific assumptions regarding the combination of the family stress and the family investment model. The observed associations do not imply causal relationships between the factors, as there might be other explanatory processes not included in the model. For example, there might be a reciprocal relationship between the child characteristics and parenting behaviour (Bell and Chapman 1986; Rutter 2002), and parenting behaviour might change over time. Also, the role of the father in supporting positive development in the face of family hardship has not been addressed. Furthermore, while family hardship and maternal distress were assessed at two time points, measures of family investment and parent-child interactions were only available at age 3 , the same age when the outcome variables were assessed. Another limitation is that, except for the assessment of cognitive ability, all other measures were obtained via maternal report, and the inclusion of some objective or independent observational data would have helped to improve the validity of the findings. It is also likely that other mediators of the 
association between family hardship and child outcomes exist that are beyond the scope of this study, as for example characteristics of the neighbourhood, or availability of social support.

Given these limitations, the findings provide some useful insights into the pathways linking family hardship to early cognitive and behavioural functioning. The findings suggest that economic hardship has a slightly stronger association with cognitive than with behavioural development, confirming evidence from previous studies (Conger and Elder 1994; Conger et al 1994; Kiernan and Huearta 2008; Linver et al 2002, Plewis and Kallis 2008; Schoon et al 2010). The study furthermore highlights the role of maternal depression as a mediator between distal and proximal experiences, and its association with good quality parent-child interactions, as well as the provision of a stimulating home environment. Of course, not all mothers suffering from depression are affected in their ability to provide a good enough, sensitive and caring environment for their children (Cicchetti, Rogosch, and Toth 1998), yet maternal depression appears to be a risk for their children's cognitive and especially behavioural adjustment. About $17 \%$ of mothers in the Millennium Cohort reported that they were depressed when their child was 9 months old, as well as at age 3 (Kiernan and Mensah 2009). Contextual risk factors such as poverty, marital conflict, and stressful life events may exacerbate maternal depression, and consequently the child's development, suggesting the importance of being vigilant in detecting or screening for maternal depression, especially among highly disadvantaged families. The findings furthermore suggest the usefulness of disentangling the emotional and cognitive components of parenting and the home environment, to gain a better understanding of the processes shaping cognitive and behavioural development. While parenting processes are more effective in mediating the influence of poverty on behavioural adjustment, they play a relative small role in mediating the effects of family hardship on cognitive development. It is therefore not enough to develop policies targeting the improvement of parenting behaviour and parental health. What is needed is a concentrated effort to reduce or eradicate child poverty and to improve the living conditions of families with young children.

The study has shown that family hardship has a direct influence on children's developmental outcomes and plays a role in shaping maternal mental health as well as parenting behaviours. Given the long-term consequences of achievement gaps emerging early in life, the fact that this gap widens throughout the childhood years (Feinstein 2003; Schoon 2006), and that children who fall behind in early development are more likely to fall further behind at subsequent stages, renders the reduction of family hardship during the first years of life a priority (Heckman 2006; Marmot 2010). The possibility of correlated unobserved characteristics and alternative mediating processes, opens the field for further investigation into the mechanisms and processes involved in the early inter-generational transmission of disadvantage. These efforts should focus their attention to both cognitive and behavioural adjustment during the early years, as both capabilities are the foundation for later developmental adjustment, and are cross-fertilizing, as shown in Duckworth and Schoon 2010 (this issue).

\section{Acknowledgements}

The analysis and writing of this paper were supported by grants from the Nuffield Foundation and the UK Economic and Social Research Council (ESRC): L326253061, RES-594-28-0001. Data from the Cohort Studies were supplied by the ESRC Data Archive. Those who carried out the original collection of the data bear no responsibility for its further analysis and interpretation. 


\section{References}

Alexander RE. (2009) Children, their world, their education: final report and recommendations of the Cambridge primary review. Routledge, London.

Becker GS and Thomes N. (1986) Human capital and the rise and fall of families. Journal of Labour Economics, 4, S1-S139.

Bell RQ and Chapman M. (1986) Child effects in studies using experimental or brief longitudinal approaches to socialization. Developmental Psychology, 22(5), 595-603.

Blanden J and Gregg P. (2004) Family income and educational attainment: a review of approaches and evidence for Britain. Oxford Review of Economic Policy, 20, 245-236.

Blanden J and Machin S. (2010) Intergenerational inequality in early years assessments. In K Hansen, H Joshi and S Dex. eds. Children of the 21st century. The first five years (pp. 153-168). Policy Press, Bristol.

Bollen KA. (1989) Structural Equations with Latent Variables. Wiley, New York.

Bradley R, Caldwell BM, Rock SL and Ramey CT. (1989) Home environment and cognitive development in the first 3 years of life: a collaborative study involving six sites and three ethnic groups in North America. Developmental Psychology, 25, 217-235.

Bradley R and Corwyn R. (2002) Socio-economic status and child development. Annual Review of Psychology, 53, 371-399.

Bronfenbrenner U. (1979) The ecology of human development : experiments by nature and design. Harvard University Press, Cambridge, MA.

Brooks-Gunn J and Duncan GJ. (1997) The effects of poverty on children. Children and Poverty, 7(2), 55-71.

Bracken BA. (2002) Bracken school readiness assessment administration manual. The Psychological Corporation, San Antonio, Texas.

Brooks-Gunn J and Duncan GJ. (1997) The effects of poverty on children. Children and Poverty, 7(2), 55-71.

Bynner J and Joshi H. (2002) Equality and opportunity in education: evidence from the 1958 and 1970 birth cohort studies. Oxford Review of Education, 28(4), 405-425.

Bynner J, Schuller T and Feinstein S. (2003) Wider benefits of education: skills, higher education and civic engagement. Zeitschrift für Pädagogik, 49(3), 341-361.

Campbell S, Cohn J and Meyers T. (1995) Depression in first-time mothers: mother-infant interaction and depression chronicity. Developmental Psychology, 31, 349-357.

Cicchetti D, Rogosch FA, and Toth SL. (1998) Maternal depressive disorder and contextual risk: contributions to the development of attachment insecurity and behavior problems in toddlerhood. Development and Psychopathology, 10(2), 283-300.

Conger KJ and Elder GH. (1994) Families in troubled times: adapting to change in rural America $\left(1^{\text {st }}\right.$ edn.) Aldine De Gruyter, New York.

Conger R, Ge X, Elder GH, Lorenz F and Simons RL. (1994) Economic stress, coercive family process, and developmental problems of adolescents. Child Development, 65, 541-561.

Cummings E and Davies P. (1994) Maternal depression and child development. Journal of Child Psychology and Psychiatry, 35, 73-112.

Downey G and Coyne JC. (1990) Children of depressed parents - an integrative review. Psychological Bulletin, 108(1), 50-76.

Duckworth K and Schoon I. 2010 Progress and attainment during primary school: the roles of literacy, numeracy and self-regulation. Longitudinal and Life Course Studies 1, 223-240.

Duncan GJ, Dowsett CJ, Claessens A, Magnuson K, Huston AC, Klebanov P, Pagani LS, Feinstein L, Engel M, Brooks-Gunn J, Sexton H, Duckworth K and Japel C. (2007) School readiness and later achievement. Developmental Psychology, 43(6), 1428-1446.

Entwistle DR and Alexander, KL. (1999) Early schooling and social stratification. In R Pianta and M Cox. eds. The transition to kindergarten (pp. 13-38). Brookes, Baltimore.

Feinstein L. (2003) Inequality in the early cognitive development of British children in the 1970 cohort. Economica, 70, 73-98.

Feinstein L. (2004) Mobility in pupils' cognitive attainment during school life. Oxford Review of Economic Policy, 20(2), 213-229.

Feinstein L and Bynner J. (2004) Mobility in pupils' cognitive attainment during school life. Oxford Review of Economic Policy, No 20.

Feinstein L and Vignoles A. (2008) Individual differences in the pathways into and beyond higher education in the UK: a life-course approach. Journal of Social Issues, 64(1), 115-133. 
George A, Hansen K and Schoon I. (2007) Child development. In K Hansen and H Joshi eds. Millennium cohort study. second survey. A user's guide to initial findings. Institute of Education, Centre for Longitudinal Studies, London.

Gershoff ET, Aber JL, Raver CC and Lennon MC. (2007) Income is not enough: incorporating material hardship into models of income associations with parenting and child development. Child Development, 78(1), 70-95.

Guo G and Harris KM. (2000) The mechanisms mediating the effects of poverty on children's intellectual development. Demography, 37(4), 431-447.

Heckman JJ. (2006) Skill formation and the economics of investing in disadvantaged children. Science, 312, 19001912.

Hills J, Sefton T and Steward K. (2009) Towards a more equal society. Poverty, inequality and policy since 1997. Policy Press, Bristol.

Janus M and Duku E. (2007) The school entry gap: socio-economic, family, and health factors associated with children's school readiness to learn. Early education and development, 18, 375-403.

Kagan SL. (1992) Readiness past, present and future. Shaping the agenda. Young Children, 48, 48-53.

Kiernan KE and Huerta MC. (2008) Economic deprivation, maternal depression, parenting and children's cognitive and emotional development in early childhood. British Journal of Sociology, 59(4), 783-806.

Kiernan KE and Mensah FK. (2009) Poverty, maternal depression, family status and children's cognitive and behavioural development in early childhood: a longitudinal study. Journal of Social Policy, 38, 569-588.

Korenman S, Miller JE and Sjaastad JE. (1995) Long-term poverty and child development: evidence from the NLSY. Children and Youth Services Review, 17(1-2), 127-155.

Linver MR, Brooks-Gunn J and Kohen DE. (2002) Family processes as pathways from income to young children's development. Developmental Psychology, 38(5), 719-734.

Lloyd JEV and Hertzman C. (2009) From kindergarten readiness to fourth-grade assessment: longitudinal analysis with linked population data. Social Science and Medicine, 68(1), 111-123.

Maclnnes T, Kenway P and Parekh A. (2009) Monitoring poverty and social exclusion. Joseph Rowntree Foundation, York.

Marmot M. (2010) Fair society healthy lives. The Marmot review: Strategic Review of Health Inequalities in England post 2010. http://www.ucl.ac.uk/gheg/marmotreview/FairSocietyHealthyLives.

McLoyd VC. (1998) Socioeconomic disadvantage and child development. American Psychologist, 53(2), $185-204$.

Melhuish E, Belsky J, Leyland,AH and Barnes J. (2008) Effects of fully-established Sure Start local programmes on 3-year-old children and their families living in England: a quasi-experimental observational study. Lancet, 372(9650), 1641-1647.

Meisels SJ. (1999) Assessing readiness. In R Pianta and M Cox. eds. The transition to kindergarten (pp. 39-66). Brookes, Baltimore.

Mistry RS, Biesanz JC, Taylor LC, Burchinal M and Cox MJ. (2004) Family income and its relation to preschool children's adjustment for families in the NICHD study of early child care. Developmental Psychology, 40(5), 727-745.

Panter JE, and Bracken BA. (2009) Validity of the Bracken School Readiness Assessment for predicting first grade readiness. Psychology in the Schools, 46(5), 397-409.

Plewis I and Kallis C. (2008) Changing economic circumstances in childhood and their effects on subsequent educational and other outcomes. DWP Working Paper No. 49. HMSO, Norwich.

Rutter M. (1989) Pathways from childhood to adult life. Journal of Child Psychology and Psychiatry and Allied Disciplines, 30(1), 23-51.

Rutter M. (2002) The interplay of nature, nurture, and developmental influences - the challenge ahead for mental health. Archives of General Psychiatry, 59(11), 996-1000.

Sameroff AJ, Seifer R, Baldwin A and Baldwin C. (1993) Stability of intelligence from preschool to adolescence the influence of social and family risk-factors. Child Development, 64(1), 80-97.

Schoon I. (2006) Risk and resilience. Adaptations in changing times. Cambridge University Press, Cambridge.

Schoon I, Bynner J, Joshi H, Parsons S, Wiggins RD and Sacker A. (2002) The influence of context, timing, and duration of risk experiences for the passage from childhood to mid-adulthood. Child Development, 73(5), 1486-1504.

Schuerger JM and Witt AC. (1989) The temporal stability of individually tested intelligence. Journal of Clinical Psychology, 45, 294-302.

Waldfogel J and Washbrook E. (2010) Low income and early cognitive development in the UK. The Sutton Trust http://www.suttontrust.com/reports/Sutton_Trust_Cognitive_Report.pdf

Yeung WJ, Linver MR and Brooks-Gunn J. (2002) How money matters for young children's development: parental investment and family processes. Child Development, 73(6), 1861-1879. 
